\title{
Pathogenesis of HIV and the Lung
}

\author{
Matthew R. Gingo, MD, $\mathbf{M S}^{1}$ and Alison Morris, MD, $\mathbf{M S}^{1,2}$ \\ Matthew R. Gingo: gingomr@upmc.edu; Alison Morris: morrisa@upmc.edu \\ ${ }^{1}$ Department of Medicine, University of Pittsburgh School of Medicine, Pittsburgh, PA, USA \\ ${ }^{2}$ Department of Immunology, University of Pittsburgh School of Medicine, Pittsburgh, PA, USA
}

\begin{abstract}
Antiretroviral therapy has improved longevity for HIV-infected persons, but long-term HIV infection is now complicated by increased rates of chronic medical conditions including pulmonary disorders. Chronic obstructive pulmonary disease, lung cancer, asthma, and pulmonary hypertension are becoming common comorbidities of HIV infection, and these diseases may develop as a result of HIV-related risk factors such as antiretroviral drug toxicities, colonization by infectious organisms, HIV viremia, immune activation, or immune dysfunction. It also appears that the ability to control HIV infection does not completely eliminate the risk for infectious complications such as bacterial pneumonia and tuberculosis. The effect of HIV infection on lungspecific immune responses is being elucidated to help develop better prevention and treatment strategies in HIV-infected persons.
\end{abstract}

\section{Keywords}

HIV; AIDS; Lung Neoplasms; Lung Diseases; Obstructive; Pulmonary Emphysema; Asthma; Pulmonary Hypertension; Pneumonia; Pneumocystis; Pneumonia; Bacterial

\section{Introduction}

Pulmonary disease has been a major co-morbidity in HIV-infected individuals since the beginning of the HIV epidemic[1]. Early in the epidemic, pulmonary infections such as bacterial pneumonia, tuberculosis, and Pneumocystis pneumonia were significant causes of morbidity and mortality[2]. Development of antiretroviral therapy (ART) has improved ability to control the HIV virus and led to improvements in longevity of persons infected with HIV. Lung diseases such as obstructive lung disease, pulmonary hypertension, and lung cancer are now emerging as significant comorbidities in the HIV-infected population. Additionally, lung infections are still a major problem in resource-limited settings. While epidemiologic evidence supports the role of HIV infection in the incidence of chronic lung disease, basic science models have highlighted mechanisms of disease pathogenesis. This review will discuss the current epidemiology of HIV-associated lung disease, explore the occurrence, risk factors, and pathogenesis of specific chronic lung diseases, and examine the role of infections and immunity in the lung in HIV-infected individuals.

Corresponding Author: Alison Morris, MD, MS, 3459 Fifth Avenue, 628 NW MUH, Pittsburgh, PA 15213, Phone: 412-624-8209, Fax: 412-624-8373.

Disclosure

M. R. Gingo: grant from NIH/NHLBI; A. Morris: grant from NIH/NHLBI. 


\section{Epidemiology}

Over the course of the AIDS epidemic, the development of both pneumonia prophylaxis and ART have led to changes in the epidemiology of HIV-associated lung diseases. A large cohort study has recently investigated prevalence and incidence of a wide array of pulmonary diagnoses in HIV-infected compared to HIV-uninfected individuals. Investigators with the Veterans Aging Cohort Study (VACS) tracked the incidence of lung disease by ICD-9 diagnosis and self-report in 33,420 HIV-infected veterans and 66,840 HIV-uninfected veterans matched by age, sex, race and ethnicity, and site[3]. The most common diseases in the HIV-infected group were bacterial pneumonia (28.0 per 1000 person-years) and chronic obstructive pulmonary disease (COPD) (20.3 per 1000 personyears). Incidence of COPD, lung cancer, pulmonary hypertension, pulmonary fibrosis, bacterial pneumonia, Pneumocystis pneumonia, and tuberculosis were all greater in the HIV-infected group. Additionally, incidence rates of pulmonary diseases increased with age, and the difference in rates between HIV-infected and uninfected persons was greatest at younger ages suggesting an earlier onset of lung disease in HIV-infected persons.

\section{Chronic obstructive lung disease/emphysema}

Prior to the introduction of ART, studies reported that HIV was associated with COPD and emphysema[4]. Current epidemiologic studies indicate that HIV continues to be an independent risk factor for COPD, and there has been a three-fold increase in obstructive lung disease deaths in HIV[5,6]. Several cohort studies have recently investigated pulmonary function in HIV-infected populations in order to quantify the extent and types of abnormalities seen and to identify factors that may contribute to these pulmonary function abnormalities (Table 1)[7-11]. Airflow obstruction measured by spirometry seems to be more prevalent than expected in HIV-infected populations. For example, a cross-sectional analysis of spirometry from $234 \mathrm{HIV}$-infected individuals found $8.6 \%$ had a force expiratory volume $\left(\mathrm{FEV}_{1}\right)$ /forced vital capacity (FVC) lower than the $5 \%$ lower limit of age, race, and gender predicted normal [8]. In this group, lower $\mathrm{FEV}_{1} / \mathrm{FVC}$ was associated with older age, smoking, history of bacterial pneumonia, and ART use. In a separate cohort of $167 \mathrm{HIV}$ infected outpatients, $21.0 \%$ had airflow obstruction (defined as $\mathrm{FEV}_{1} / \mathrm{FVC}<0.7$ ); and airflow obstruction was associated with smoking, intravenous drug use and ART [9]. Another cohort of 98 individuals had a $16.3 \%$ prevalence of obstructive lung disease $\left(\mathrm{FEV}_{1} /\right.$ $\mathrm{FVC}<0.70$ and an $\mathrm{FEV}_{1}<80 \%$ predicted) which was associated with age, smoking, intravenous drug use, and history of Pneumocystis pneumonia [10]. In a cohort of intravenous drug abusers, obstructive lung disease $\left(\mathrm{FEV}_{1} / \mathrm{FVC}<0.70\right)$ was present in $16.8 \%$ of HIV-infected participants[7]. HIV-infected participants with a viral load $>200,000$ copies/ $\mathrm{mL}$ were about 3.4 times more likely to have obstructive lung disease than HIV-uninfected participants, but those with controlled viral loads were no more likely to have obstruction than the HIV-uninfected participants.

Emphysema is a phenotype of obstructive lung disease characterized by anatomic destruction of lung parenchyma that has long been seen in HIV infection. Diffusing capacity for carbon monoxide $\left(\mathrm{DL}_{\mathrm{CO}}\right)$ is a marker of emphysema as well as other pulmonary disorders and was noted to be abnormal prior to the introduction of ART. Diffusion impairment appears to remain a common abnormality in the current HIV era. In one recent study, $64 \%$ of HIV-infected individuals had a $\mathrm{DL}_{\mathrm{CO}}<80 \%$ predicted [9], and in another, $43 \%$ had a $\mathrm{DL}_{\mathrm{CO}}<1.645$ residual standard deviations below predicted values [11]. While diffusing impairment was worse in smokers, the prevalence of impaired diffusion capacity in never smokers was $48 \%$ and $9 \%$ in the two studies, respectively. A reduced diffusing capacity was associated with smoking and use of pneumonia prophylaxis,[9] and in longitudinal follow-up, $\mathrm{DL}_{\mathrm{CO}}$ declined significantly and to a greater degree than other lung 
function parameters [11]. Additionally, a comparison of lung function between 229 HIVinfected and 213 HIV-uninfected participants from the Multicenter AIDS Cohort and VACS studies found that HIV infection was independently associated with impaired diffusing capacity[12].

The decrease in DLco likely has significant clinical relevance. In our experience, lower $\mathrm{DL}_{\mathrm{CO}}$ is a significant predictor of mortality (Morris, unpublished data). In a cohort of 237 HIV-infected participants followed for 3 years on average, individuals who died had a significantly lower DLco (51.3\% predicted versus $66.0 \%$ predicted, $\mathrm{p}=0.004)$ (Figure 1). The odds of death if the DLco was below $60 \%$ predicted were significantly greater independent of age, smoking history, ART use, and CD4 cell count (adjusted odds ratio $=6.31,95 \%$ confidence interval $=1.21-32.9, \mathrm{p}=0.029$ )(Morris, unpublished data). These findings suggest that lung diseases in HIV-infected individuals are an important health concern and either directly contribute to mortality or are a marker of an underlying systemic process.

Cigarette smoke is clearly the leading risk factor for COPD/emphysema in HIV, but there are likely additional causes of COPD in HIV as the disease appears to be accelerated in HIV-infected smokers and is seen even in non-smokers. Poorly controlled HIV has been associated with worse pulmonary function[3,7]. In the VACS study, lung diseases such as asthma and COPD were less likely in those with lower HIV RNA levels and use of antiretroviral therapy (ART) at baseline. A study that directly measured pulmonary function also found that individuals with HIV viral levels above 200,000 copies/ml had worse airway obstruction[7]. These studies suggest either a direct viral effect or effects of HIV sequelae such as infections in development of COPD. Although more severe immunosuppression has been associated with COPD, two studies have found that use of ART is also associated with worse lung function[8,9]. These apparently contradictory findings could be explained potentially by differences in timing of ART initiation between populations, with those experiencing worse lung function on ART when it is initiated at a lower CD4 cell count, potentially from increases in autoimmunity or renewed immunologic response to low-level lung pathogens $[13,14]$.

The relationship of colonizing microbial pathogens to COPD in HIV has been recently investigated, and several studies have implicated colonization with Pneumocystis jirovecii, a common HIV-associated infection, in the pathogenesis of obstructive lung disease in HIV. In a cohort of 42 HIV-infected individuals, those with Pneumocystis jirovecii detectable only by nested PCR of the mitochondrial large subunit rRNA in oral washes or induced sputum had worse airflow and more obstructive lung disease by pulmonary function studies [15]. In macaque models of HIV infection, monkeys that become colonized with Pneumocystis (detection of Pneumocystis DNA in lung or airway samples) develop worse airflow obstruction and emphysema[16,17]. A non-immunosuppressed rodent model has also shown development of COPD-like changes in mice exposed to both cigarette smoke and Pneumocystis[18]. HIV infection is associated with a greater probability of colonization with Pneumocystis which may explain in part the increased prevalence of obstructive lung disease in HIV-infected persons [19]. Other factors associated with HIV infection including increased oxidative stress, cellular senescence, the lung microbiome community, and immune activation could also play a role in HIV-associated COPD.

\section{Asthma}

Asthma is characterized by airway inflammation and inducible or reversible airway obstruction (airway hyperreactivity) and can lead to significant morbidity such as episodes of dyspnea and functional impairment. Prior to ART, asthma and airway hyperreactivity 
were common in HIV infection and related to smoking and possibly to atopy [20,21]. In the ART era, findings regarding the prevalence of asthma are uncertain. In the VACS cohort which was predominantly older male smokers, asthma diagnosis was not any more common in HIV-infected individuals [3]. However, two recent studies have found $11 \%$ and $21 \%$ of HIV-infected persons had an asthma diagnosis by history (doctor-diagnosed asthma),[22,23] with a prevalence of approximately $9 \%$ in the general population[24,25]. Pulmonary function testing in these studies found $4 \%$ and $9 \%$ had bronchodilator reversibility by American Thoracic Society/European Respiratory Society criteria, again what may be higher than expected in the general population[25]. In the later study, doctor-diagnosed asthma was associated with female sex, being obese, not being on ART, and a history of bacterial or Pneumocystis pneumonia, and there was a strong association between doctor-diagnosed asthma and high sputum eosinophil counts. In addition, approximately $10 \%$ of the cohort had high sputum eosinophil counts, suggesting an increase in Th2 type inflammation in the airways of HIV-infected persons, and there were associations between asthma diagnosis or bronchodilator response and sputum and serum cytokines that are also related to chronic HIV infection: RANTES and macrophage inflammatory protein-1a and $-1 \beta[26]$. Interestingly, $55 \%$ of the HIV-infected individuals reported onset of asthma as an adult, often after diagnosis of HIV. In contrast, the majority of asthma diagnoses in the general population occur in children. These studies suggest that asthma is an important manifestation of lung disease in HIV-infected individuals and there may be a distinct phenotype associated with HIV. Allergy/atopy, metabolic disease, and chronic inflammation possibly stimulated by underlying infections could be important mechanisms causing airway inflammation in HIV.

\section{Lung Cancer}

The influence of HIV infection on lung cancer risk has been debated since early in the HIV epidemic. Taken as a whole, the recent literature would suggest HIV is currently an independent risk for lung cancer. In 2009, a meta-analysis examined studies using cancer registries or Surveillance Epidemiology and End Results (SEER) data to compare cancer rates in HIV populations to the general population [27]. HIV infection was associated with a standardized incidence ratio (SIR) of 2.6 (95\% CI, 2.1-3.1). While this study provided a powerful assessment of the risk HIV may contribute to lung cancer, it also highlights the limitations that many studies assessing lung cancer risk have: lack of prospectively collected data, inadequate comparison group, and limited ability to control for other lung cancer risk factors such as smoking or other behaviors.

Retrospective analyses of large administrative and clinical data have attempted to address some of these issues. A cohort of 5,053 HIV-infected persons in the Danish HIV Cohort Study were matched by age and sex to 50,530 HIV-uninfected persons [28]. The adjusted IRR was 2.38 (95\% CI, 1.61-3.53). Parents of HIV-infected individuals had an elevated risk of lung cancer compared to the Danish population, suggesting there may have been genetic susceptibility or even greater exposure to risk factors (such as childhood second-hand smoke exposure) in the HIV-infected cohort. Another study linked VACS Virtual Cohort data with the Veterans Affairs Central Cancer Registry and found HIV infection was associated with a 1.7-fold (95\% CI, 1.5-1.9) greater risk of lung cancer when controlling for age, sex, race/ ethnicity, smoking prevalence, prior bacterial pneumonia, and history of COPD [29]. Two studies of the California Kaiser Permanente integrated health delivery system assessed lung cancer risk in over 20,000 HIV-infected versus approximately 200,000 HIV-uninfected individuals. The incidence rate ratio (IRR) in HIV-infected versus HIV-uninfected was 1.9 (95\% CI, 1.4-2.5) controlling for age, sex, calendar year, and race/ethnicity [30]. However, in a subsequent study they collected data on smoking, BMI, and alcohol/drug abuse, and when controlling for these factors, the IRR was 1.2 (95\% CI, 0.9-1.6), suggesting that the 
difference in lung cancer rates between HIV-infected and HIV-uninfected persons may be related to an excess of risk factors in the HIV-infected population [31].

Several prospective studies have also attempted to assess the independent risk of HIV in lung cancer. A study from the Women's Interagency HIV Cohort following 2,651 HIVinfected and 898 HIV-uninfected women with similar HIV risk factors found the SIRs were significantly greater than SEER data for both groups, but there was no difference in lung cancer rates between the HIV-infected and HIV-uninfected groups [32]. A similar study of cancer incidence in the Multicenter AIDS Cohort Study of 6,972 men who have sex with men found the hazard ratio for lung cancer during the ART era in HIV+ to be 5.98 (95\% CI, 0.47-320.86), but this ratio was not significant because of very few numbers of lung cancer cases (3 in HIV-infected versus 1 in HIV-uninfected) [33]. A recent study of lung cancer risk found in a cohort of 2,495 injection drug users in Baltimore, MD that HIV infection was associated with a 2.3 times (95\% CI, 1.1-5.1) increase in the risk of lung cancer controlling for age, gender, and average packs smoked per day [34]. These prospective studies may not reveal as dramatic evidence of HIV as a risk for lung cancer as the larger retrospective cohort studies because they are able to more accurately control for confounding of other potential lung cancer risk factors such as smoking. However, there are still strong trends and some studies show statistical significance despite having few numbers, suggesting HIV to be a true risk factor for lung cancer.

Factors responsible for the potential increase in lung cancer related to HIV infection are not clear. Nearly all studies of lung cancer in HIV show that smoking is a strong risk factor for lung cancer in HIV-infected individuals, but do not find a significant interaction between the two. Immune function and immune surveillance are important mechanisms controlling tumorigenesis,[35] and it is suspected that immune deficiency related to HIV infection may be an important risk factor for lung cancer in HIV. Several studies show that risk of lung cancer in HIV-infected individuals increases with lower CD4 count[28,31] or higher plasma HIV RNA level[31] and is increased in those with a history of AIDS [27,36]. However, not all studies find these associations [3,29,37,38]. There also does not appear to be an association between ART use and lung cancer in HIV-infected persons[3,29]. Absolute numbers of lung cancers in HIV-infected persons are increasing as the population gets bigger, and there is less competing risk from AIDS-related conditions with more effective treatment[39]. However, the SIR compared to the HIV-uninfected population seems to be declining over time [30,40]. This decrease could be due to better HIV control and immune restoration with more effective treatments or to changes in risk behaviors.

While survival in lung cancer is poor in general, HIV infection may portend an even worse prognosis. Some studies have found that survival is worse in those with HIV infection, although some reports have found similar survival to the HIV-uninfected population $[28,34,37,41]$. Study results of mortality may be confounded by the increased likelihood of other causes of death in HIV-infected persons [41]. HIV-infected individuals are at greater risk for serious hematotoxicity with chemotherapeutic agents likely related to interactions with ART [42]. Survival in HIV-infected individuals with lung cancer is related to better performance status at diagnosis, higher CD4 count, early stage at diagnosis, and use of ART [42-44].

\section{Pulmonary Hypertension}

Pulmonary arterial hypertension was recognized early in the AIDS epidemic as having an increased prevalence in HIV-infected individuals[45]. In the current era, the VACS study found the overall baseline prevalence for pulmonary hypertension was low $(0.2 \%$ in HIVinfected and $0.16 \%$ in HIV-uninfected individuals), but HIV-infected veterans were around 
1.5 times more likely to be diagnosed with pulmonary hypertension during study followup[3]. While the diagnosis of primary pulmonary hypertension is rare, other more common processes such as primary lung or cardiac disease, inflammatory disease, or veno-embolic disease can lead to pulmonary vascular disease and elevated pulmonary artery pressures. Two recent studies show echocardiographic findings of pulmonary hypertension are common among HIV-infected persons [46,47]. In 656 HIV-infected individuals, 57\% had an abnormal estimated pulmonary artery systolic pressure of $>30 \mathrm{mmHg}$ and $7 \%$ had pressures $>40 \mathrm{mmHg}$, although this prevalence may be slightly overestimated because of methodological issues related to the estimate of pulmonary artery pressures $[46,48]$. However, a study in another cohort using methods addressing those possible limitations found $66 \%$ of participants had pressures $\geq 30 \mathrm{mmHg}$, and $16 \%$ had pressures $\geq 40 \mathrm{mmHg}$ [47]. In the later study, elevated pulmonary artery pressures were associated with worse respiratory symptoms, poorer lung function, more advanced HIV disease, and markers of inflammation and T-cell activation.

The increased risk for pulmonary hypertension and the relationship between pulmonary hypertension and increased morbidity in HIV-infected individuals make understanding pulmonary hypertension in this population an important area of inquiry. The HIV virus may have direct pathologic effect on pulmonary vasculature by causing endothelial dysfunction. HIV Nef protein has been implicated in this process by several studies [49-52]. HIV Nef reduces endothelial nitric oxide synthase (eNOS) and induces oxidative stress in human pulmonary artery endothelial cells [50]. In a macaque model of HIV infection with simian immunodeficiency virus (SIV)/HIV hybrid virus (SHIV) with HIV Nef protein, Nef leads to Golgi dysfunction in endothelial cells, and Golgi dysfunction is also seen in human endothelial cells from HIV-infected individuals [51]. Additionally, HIV Nef gene polymorphisms have been associated with pulmonary arterial hypertension in HIV-infected individuals suggesting a functional role for HIV Nef [49]. However, there may be other mechanisms unrelated to HIV Nef since macaques infected with SHIV-env virus (which does not contain HIV Nef protein) also develop vascular changes associated with pulmonary arterial hypertension [53]. In addition to HIV proteins, there may be an interaction between HIV infection and use of illicit drugs. Cocaine and morphine have each been implicated in enhancing the effect of HIV-mediated pulmonary endothelial and smooth muscle dysfunction, [54,55] which is important given the high prevalence of injection drug use in the HIV population.

Survival with HIV-associated pulmonary hypertension may be improving with better HIV treatment and use of pulmonary hypertension medications. Although some studies have found increased risk with certain ART medications, other studies find that ART improves pulmonary hypertension[56,57]. Agents that target pulmonary hypertension in the HIVuninfected population may also work in those with HIV. In a cohort of 77 HIV-infected participants, 50 were started on specific pulmonary arterial hypertension therapy (intravenous epoprostenol in three patients, inhaled iloprost in one, and bosentan in 45 patients, and a calcium channel blocker was initiated in one who responded acutely to nitric oxide) and had improvement in their six-minute walk distances and hemodynamic parameters [58]. With a mean follow-up of 42 months, overall survival was 88, 72, and 63\% at 1,3 , and 5 years, respectively, which is better than previously observed in HIV-associated pulmonary hypertension series, but worse than expected survival after first AIDS-defining illness [58]. Additionally, poor HIV control (low CD4 count, detectable HIV RNA) and factors related to worse pulmonary hypertension (history of right heart failure, New York Heart Association functional class IV, or worse cardiac index) were associated with worse survival. These data highlight the impact on survival and the importance of appropriate evaluation and treatment of pulmonary hypertension in HIV-infected patients. 


\section{Pneumonia}

Tuberculosis, bacterial, and Pneumocystis pneumonia continue to cause a significant burden of morbidity in HIV-infected persons. The VACS investigators found all three of these pneumonias were drastically more common in HIV-infected veterans[3]. In a cohort of 736 children, incidence of community-acquired pneumonia has decreased from the period of 2000-2005, but it was found that poor HIV control was associated with increased risk of community-acquired pneumonia (a CD4\% $<15 \%$ or HIV viral load $>100,000$ copies $/ \mathrm{mL}$ )[59]. In a region with universal access to HIV care and pneumococcal vaccination, the incidence of invasive pneumococcal disease (pneumococcal pneumonia or bacteremia, mainly) was $342 / 100,000$ person-years [60]. Incidence was lower in those vaccinated with 23-valent pneumococcal vaccine, but high HIV RNA levels at the time of vaccination was associated with vaccine failure, suggesting that better HIV control was important in developing protective immunity with pneumococcal vaccine. In a series of $147 \mathrm{HIV}$-infected patients admitted with acute respiratory failure to a university hospital ICU in Paris, France between 1996 and 2006, the cause of acute respiratory failure was bacterial pneumonia in 50.3\% and Pneumocystis pneumonia in $35.4 \%$ [61]. Hospital mortality was $24.3 \%$ and $15.3 \%$, respectively, and was mainly influenced by number and severity of organ failures at admission and during ICU, but not by extent of immunodeficiency. However, compared to studies from the pre-ART era, hospital mortality from acute respiratory failure has improved [61]. While HAART therapy has drastically reduced the incidence of tuberculosis,[62,63] HIV and tuberculosis co-infections are on the rise[64]. HIV-infected individuals account for a large proportion of the world-wide tuberculosis burden (approximately 13\% of tuberculosis cases occur in HIV-infected individuals) and an even greater proportion of tuberculosis-related deaths (approximately 24\%)[64]. Part of this may be due to an increased risk for primary drug-resistant tuberculosis with HIV infection[65]. However, immune suppression and tuberculosis infection are clearly associated with worse outcomes[66]. Several recent studies have addressed timing of starting antiretroviral in HIV-infected patients with active tuberculosis to help improve immune function to combat active tuberculosis infection [67-69]. These studies randomized 1,899 participants early (within 24 weeks of starting tuberculosis treatment) vs. late (8-12 weeks after starting tuberculosis treatment) initiation of antiretroviral treatment. While there was an increase in immune reconstitution inflammatory syndrome with early treatment, two studies showed no difference in AIDS-related death,[67,69] and the third showed a decrease in overall mortality[68]. For participants with CD4 counts $<50$ cells/ $\mu \mathrm{L}$, early initiation of antiretroviral therapy was associated with a decrease in mortality[68,69]. Despite the effectiveness of antiretroviral therapy, pulmonary infections continue to be a significant source of morbidity and mortality in HIV infection, especially with the threat of drugresistant tuberculosis.

\section{Pulmonary immune response in HIV}

A small number of studies recently have detailed some aspects of the immune responses in the lung of HIV-infected patients. These findings may explain in part the continued increase risk for pulmonary infections [70-74]. In a study that explored blood and alveolar lymphocytes in HIV-infected and HIV-uninfected persons with Pneumocystis pneumonia, lower alveolar CD4+ T-cells was predictive of Pneumocystis pneumonia, and alveolar CD4+ T-cell numbers were strongly correlated with peripheral CD4+ T-cell counts in HIVinfected, but not HIV-uninfected subjects, illustrating the relationship between lung immune function and systemic immune function in HIV[71]. In addition, alveolar CD4+ T-cell function is impaired in HIV-infected compared to HIV-uninfected persons with HIVinfected individuals having a lower frequency of antigen specific CD4+ T-cells against influenza, Streptococcus pneumoniae, and Mycobacterium tuberculosis and impaired 
influenza and Mycobacterium tuberculosis specific CD4+ T-cells responses[72]. HIV also decreases alveolar macrophage response to bacteria through Toll-like receptor 4 signaling through a myeloid differentiation factor 88 dependent pathway[74]. These studies illustrate mechanisms related to increased infections even in well controlled HIV-infected persons and suggest possible targets for future therapies.

\section{Conclusion}

While antiretroviral therapy has improved control of HIV infection, lung disease is still a significant problem in HIV. Obstructive lung disease, pulmonary hypertension, and lung cancer more commonly plague the HIV-infected population, and lung infections continue to occur. Basic science and translational research are starting to identify some mechanisms of disease pathogenesis that may provide future targets for prevention and treatment of HIVrelated lung disease including the role of colonizing infections, and defects in pulmonary immunity. Continuing studies of pulmonary disease in HIV are important as the epidemic continues to evolve.

\section{References}

1. Murray JF, Felton CP, Garay SM, et al. Pulmonary complications of the Acquired Immunodeficiency Syndrome. Report of a National Heart, Lung, and Blood Institute workshop. N Engl J Med. 1984; 310(25):1682-8. [PubMed: 6328301]

2. Murray JF, Garay SM, Hopewell PC, et al. NHLBI workshop summary. Pulmonary complications of the Acquired Immunodeficiency Syndrome: an update. Report of the second National Heart, Lung and Blood Institute workshop. Am Rev Respir Dis. 1987; 135(2):504-9. [PubMed: 3813212]

3••. Crothers K, Huang L, Goulet JL, et al. HIV infection and risk for incident pulmonary diseases in the combination antiretroviral therapy era. Am J Respir Crit Care Med. 2011; 183(3):388-95. A study of 33,420 HIV-infected veterans and 66,840 HIV-uninfected veterans matched by age, sex, race and ethnicity, and site that demonstrated that HIV infection was associated with increased incidence of COPD, lung cancer, pulmonary hypertension, lung fibrosis, tuberculosis, bacterial pneumonia, and Pneumocystis pneumonia. [PubMed: 20851926]

4. Diaz PT, King MA, Pacht ER, et al. Increased susceptibility to pulmonary emphysema among HIVseropositive smokers. Ann Intern Med. 2000; 132(5):369-72. [PubMed: 10691587]

5. Morris AM, Huang L, Bacchetti P, et al. Permanent declines in pulmonary function following pneumonia in human immunodeficiency virus-infected persons. The Pulmonary Complications of HIV Infection Study Group. Am J Respir Crit Care Med. 2000; 162(2 Pt 1):612-6. [PubMed: 10934095]

6. Louie JK, Hsu LC, Osmond DH, et al. Trends in causes of death among persons with acquired immunodeficiency syndrome in the era of highly active antiretroviral therapy, San Francisco, 19941998. J Infect Dis. 2002; 186(7):1023-7. [PubMed: 12232845]

7. Drummond MB, Kirk GD, Astemborski J, et al. Association between obstructive lung disease and markers of HIV infection in a high-risk cohort. Thorax. 2012; 67(4):309-14. [PubMed: 22090038]

8. George MP, Kannass M, Huang L, et al. Respiratory symptoms and airway obstruction in HIVinfected subjects in the haart era. PLoS One. 2009; 4(7):e6328. [PubMed: 19621086]

9•. Gingo MR, George MP, Kessinger CJ, et al. Pulmonary function abnormalities in HIV-infected patients during the current antiretroviral therapy era. Am J Respir Crit Care Med. 2010; 182(6): 790-6. Demonstrated a high prevalence of irreversible airflow obstruction and abnormal pulmonary diffusing capacity even in never-smokers. Supported prior finding that airflow obstruction was associated with ART use. [PubMed: 20522793]

10. Hirani A, Cavallazzi R, Vasu T, et al. Prevalence of obstructive lung disease in HIV population: a cross sectional study. Respir Med. 2011; 105(11):1655-61. [PubMed: 21703841]

11. Kristoffersen US, Lebech AM, Mortensen J, et al. Changes in lung function of HIV-infected patients: a 4.5-year follow-up study. Clin Physiol Funct Imaging. 2012; 32(4):288-95. [PubMed: 22681606] 
12. Crothers, K.; Kleerup, EC.; Wongtrakool, C., et al. HIV infection is associated with impaired pulmonary diffusing capacity. [abstract \#819]. Presented at the 19th Conference on Retroviruses and Oppurtunistic Infections; Seattle, Washington. March 5-8, 2012;

13. Crothers K, Huang L. Pulmonary complications of immune reconstitution inflammatory syndromes in HIV-infected patients. Respirology. 2009; 14(4):486-94. [PubMed: 19192228]

14. Mori S, Levin P. A brief review of potential mechanisms of immune reconstitution inflammatory syndrome in HIV following antiretroviral therapy. Int J STD AIDS. 2009; 20(7):447-52. [PubMed: 19541884]

15. Morris A, Alexander T, Radhi S, et al. Airway obstruction is increased in pneumocystis-colonized human immunodeficiency virus-infected outpatients. J Clin Microbiol. 2009; 47(11):3773-6. [PubMed: 19759224]

16. Kling HM, Shipley TW, Patil SP, et al. Relationship of Pneumocystis jiroveci humoral immunity to prevention of colonization and chronic obstructive pulmonary disease in a primate model of HIV infection. Infect Immun. 2010; 78(10):4320-30. [PubMed: 20660609]

17•. Shipley TW, Kling HM, Morris A, et al. Persistent Pneumocystis colonization leads to the development of chronic obstructive pulmonary disease in a nonhuman primate model of AIDS. J Infect Dis. 2010; 202(2):302-12. Demonstrates in a non-human primate model that colonization with Pneumocystis leads to airflow obstruction and emphysematous changes in the lung. This study supports Pneumocystis colonization as a causative agent for chronic obstructive pulmonary disease, which has therapeutic implications for chronic obstructive pulmonary disease in humans. [PubMed: 20533880]

18. Christensen PJ, Preston AM, Ling T, et al. Pneumocystis murina infection and cigarette smoke exposure interact to cause increased organism burden, development of airspace enlargement, and pulmonary inflammation in mice. Infect Immun. 2008; 76(8):3481-90. [PubMed: 18490462]

19. Morris A, George MP, Crothers K, et al. HIV and chronic obstructive pulmonary disease: is it worse and why? Proc Am Thorac Soc. 2011; 8(3):320-5. [PubMed: 21653535]

20. Poirier CD, Inhaber N, Lalonde RG, et al. Prevalence of bronchial hyperresponsiveness among HIV-infected men. Am J Respir Crit Care Med. 2001; 164(4):542-5. [PubMed: 11520712]

21. Wallace JM, Stone GS, Browdy BL, et al. Nonspecific airway hyperresponsiveness in HIV disease. Pulmonary Complications of HIV Infection Study Group. Chest. 1997; 111(1):121-7. [PubMed: 8996005]

22. Cui Q, Carruthers S, McIvor A, et al. Effect of smoking on lung function, respiratory symptoms and respiratory diseases amongst HIV-positive subjects: a cross-sectional study. AIDS Res Ther. 2010; 7:6. [PubMed: 20298614]

23. Gingo MR, Wenzel SE, Steele C, et al. Asthma diagnosis and airway bronchodilator response in hiv-infected patients. J Allergy Clin Immunol. 2012; 129(3):708-14. e8. First study to report on asthma diagnosis and bronchodilator response and potential mechanisms in HIV-infected persons during the effective ART era. [PubMed: 22177327]

24. Bridevaux PO, Probst-Hensch NM, Schindler C, et al. Prevalence of airflow obstruction in smokers and never-smokers in switzerland. Eur Respir J. 2010; 36(6):1259-69. [PubMed: 20413537]

25. Appleton SL, Adams RJ, Wilson DH, et al. Spirometric criteria for asthma: adding further evidence to the debate. J Allergy Clin Immunol. 2005; 116(5):976-82. [PubMed: 16275363]

26. Cocchi F, DeVico AL, Garzino-Demo A, et al. Identification of RANTES, MIP-1 alpha, and MIP-1 beta as the major HIV-suppressive factors produced by CD8+ t cells. Science. 1995; 270(5243):1811-5. [PubMed: 8525373]

27. Shiels MS, Cole SR, Kirk GD, et al. A meta-analysis of the incidence of non-AIDS cancers in HIV-infected individuals. J Acquir Immune Defic Syndr. 2009; 52(5):611-22. [PubMed: 19770804]

28. Engsig FN, Kronborg G, Larsen CS, et al. Lung cancer in HIV patients and their parents: a danish cohort study. BMC Cancer. 2011; 11:272. [PubMed: 21702995]

29. Sigel K, Wisnivesky J, Gordon K, et al. HIV as an independent risk factor for incident lung cancer. AIDS. 2012; 26(8):1017-25. [PubMed: 22382152] 
30. Silverberg MJ, Chao C, Leyden WA, et al. HIV infection and the risk of cancers with and without a known infectious cause. AIDS. 2009; 23(17):2337-45. [PubMed: 19741479]

31. Silverberg MJ, Chao C, Leyden WA, et al. HIV infection, immunodeficiency, viral replication, and the risk of cancer. Cancer Epidemiol Biomarkers Prev. 2011; 20(12):2551-9. [PubMed: 22109347]

32. Levine AM, Seaberg EC, Hessol NA, et al. HIV as a risk factor for lung cancer in women: data from the Women's Interagency HIV Study. J Clin Oncol. 2010; 28(9):1514-9. [PubMed: 20177022]

33. Seaberg EC, Wiley D, Martinez-Maza O, et al. Cancer incidence in the Multicenter AIDS Cohort Study before and during the HAART era: 1984 to 2007. Cancer. 2010; 116(23):5507-16. [PubMed: 20672354]

34. Shiels MS, Cole SR, Mehta SH, et al. Lung cancer incidence and mortality among HIV-infected and HIV-uninfected injection drug users. J Acquir Immune Defic Syndr. 2010; 55(4):510-5. [PubMed: 20838223]

35. Shankaran V, Ikeda H, Bruce AT, et al. IFNgamma and lymphocytes prevent primary tumour development and shape tumour immunogenicity. Nature. 2001; 410(6832):1107-11. [PubMed: 11323675]

36. Dal Maso L, Polesel J, Serraino D, et al. Pattern of cancer risk in persons with AIDS in Italy in the HAART era. Br J Cancer. 2009; 100(5):840-7. [PubMed: 19223894]

37. D'Jaen GA, Pantanowitz L, Bower M, et al. Human immunodeficiency virus-associated primary lung cancer in the era of highly active antiretroviral therapy: a multi-institutional collaboration. Clin Lung Cancer. 2010; 11(6):396-404. [PubMed: 21062730]

38. Clifford GM, Lise M, Franceschi S, et al. Lung cancer in the swiss HIV cohort study: role of smoking, immunodeficiency and pulmonary infection. Br J Cancer. 2012; 106(3):447-52. [PubMed: 22240797]

39. Simard EP, Pfeiffer RM, Engels EA. Cumulative incidence of cancer among individuals with Acquired Immunodeficiency Syndrome in the United States. Cancer. 2011; 117(5):1089-96. [PubMed: 20960504]

40. Shiels MS, Pfeiffer RM, Gail MH, et al. Cancer burden in the HIV-infected population in the United States. J Natl Cancer Inst. 2011; 103(9):753-62. [PubMed: 21483021]

41. Lee JY, Moore PC, Lensing SY. Impact of HIV infection on medicare beneficiaries with lung cancer. J Cancer Epidemiol. 2012; 2012:706469. [PubMed: 22548059]

42. Makinson A, Tenon JC, Eymard-Duvernay S, et al. Human immunodeficiency virus infection and non-small cell lung cancer: survival and toxicity of antineoplastic chemotherapy in a cohort study. J Thorac Oncol. 2011; 6(6):1022-9. [PubMed: 21512403]

43. Lavole A, Chouaid C, Baudrin L, et al. Effect of highly active antiretroviral therapy on survival of HIV infected patients with non-small-cell lung cancer. Lung Cancer. 2009; 65(3):345-50. [PubMed: 19135758]

44. Pakkala S, Chen Z, Rimland D, et al. Human immunodeficiency virus-associated lung cancer in the era of highly active antiretroviral therapy. Cancer. 2012; 118(1):164-72. [PubMed: 21713759]

45. Speich R, Jenni R, Opravil M, et al. Primary pulmonary hypertension in HIV infection. Chest. 1991; 100(5):1268-71. [PubMed: 1935280]

46. Mondy KE, Gottdiener J, Overton ET, et al. High prevalence of echocardiographic abnormalities among HIV-infected persons in the era of highly active antiretroviral therapy. Clin Infect Dis. 2011; 52(3):378-86. [PubMed: 21217185]

47. Morris A, Gingo MR, George MP, et al. Cardiopulmonary function in individuals with HIV infection in the antiretroviral therapy era. Aids. 2012; 26(6):731-40. [PubMed: 22210636]

48. Hsue PY, Bolger AF, Martin JN. Pulmonary hypertension in HIV-infected individuals. Clin Infect Dis. 2011; 53(1):96. author reply 96-7. [PubMed: 21653312]

49. Almodovar S, Knight R, Allshouse AA, et al. Human Immunodeficiency Virus nef signature sequences are associated with pulmonary hypertension. AIDS Res Hum Retroviruses. 2012; 28(6): 607-18. [PubMed: 22066947] 
50. Duffy P, Wang X, Lin PH, et al. HIV nef protein causes endothelial dysfunction in porcine pulmonary arteries and human pulmonary artery endothelial cells. J Surg Res. 2009; 156(2):25764. [PubMed: 19540523]

51. Sehgal PB, Mukhopadhyay S, Patel K, et al. Golgi dysfunction is a common feature in idiopathic human pulmonary hypertension and vascular lesions in SHIV-nef-infected macaques. Am J Physiol Lung Cell Mol Physiol. 2009; 297(4):L729-37. [PubMed: 19648286]

52. Marecki JC, Cool CD, Parr JE, et al. HIV-1 nef is associated with complex pulmonary vascular lesions in SHIV-nef-infected macaques. Am J Respir Crit Care Med. 2006; 174(4):437-45. [PubMed: 16728715]

53. George MP, Brower A, Kling H, et al. Pulmonary vascular lesions are common in SIV- and SHIVenv-infected macaques. AIDS Res Hum Retroviruses. 2011; 27(2):103-11. [PubMed: 20961277]

54•. Dhillon NK, Li F, Xue B, et al. Effect of cocaine on human immunodeficiency virus-mediated pulmonary endothelial and smooth muscle dysfunction. Am J Respir Cell Mol Biol. 2011; 45(1): 40-52. Identified that cocaine has an additive effect with HIV infection on endothelial dysfunction and pulmonary smooth muscle cell proliferation prliferation through disruption of tight junction proteins and increased platelet-derived growth factor expression. [PubMed: 20802087]

55. Spikes L, Dalvi P, Tawfik O, et al. Enhanced pulmonary arteriopathy in simian immunodeficiency virus-infected macaques exposed to morphine. Am J Respir Crit Care Med. 2012; 185(11):123543. [PubMed: 22447963]

56. Zuber JP, Calmy A, Evison JM, et al. Pulmonary arterial hypertension related to HIV infection: improved hemodynamics and survival associated with antiretroviral therapy. Clin Infect Dis. 2004; 38(8):1178-85. [PubMed: 15095226]

57. Opravil M, Pechere M, Speich R, et al. HIV-associated primary pulmonary hypertension. A case control study. Swiss HIV Cohort Study. Am J Respir Crit Care Med. 1997; 155(3):990-5. [PubMed: 9117037]

58. Degano B, Guillaume M, Savale L, et al. HIV-associated pulmonary arterial hypertension: survival and prognostic factors in the modern therapeutic era. AIDS. 2010; 24(1):67-75. [PubMed: 19770696]

59. Steenhoff AP, Josephs JS, Rutstein RM, et al. Incidence of and risk factors for community acquired pneumonia in US HIV-infected children, 2000-2005. AIDS. 2011; 25(5):717-20. [PubMed: 21252630]

60. Siemieniuk RA, Gregson DB, Gill MJ. The persisting burden of invasive pneumococcal disease in HIV patients: an observational cohort study. BMC Infect Dis. 2011; 11:314. [PubMed: 22078162]

61. Barbier F, Coquet I, Legriel S, et al. Etiologies and outcome of acute respiratory failure in HIVinfected patients. Intensive Care Med. 2009; 35(10):1678-86. [PubMed: 19575179]

62. Lawn SD, Badri M, Wood R. Tuberculosis among HIV-infected patients receiving HAART: long term incidence and risk factors in a South African cohort. AIDS. 2005; 19(18):2109-16. [PubMed: 16284460]

63. Miranda A, Morgan M, Jamal L, et al. Impact of antiretroviral therapy on the incidence of tuberculosis: the brazilian experience, 1995-2001. PLoS One. 2007; 2(9):e826. [PubMed: 17786198]

64. World Health Organization. Global tuberculosis control 2011. Geneva, Switzerland: WHO; 2011.

65. Wright A, Zignol M, Van Deun A, et al. Epidemiology of antituberculosis drug resistance 200207: an updated analysis of the global project on anti-tuberculosis drug resistance surveillance. Lancet. 2009; 373(9678):1861-73. [PubMed: 19375159]

66. Dheda K, Shean K, Zumla A, et al. Early treatment outcomes and HIV status of patients with extensively drug-resistant tuberculosis in South Africa: a retrospective cohort study. Lancet. 2010; 375(9728):1798-807. [PubMed: 20488525]

67. Abdool Karim SS, Naidoo K, Grobler A, et al. Integration of antiretroviral therapy with tuberculosis treatment. N Engl J Med. 2011; 365(16):1492-501. [PubMed: 22010915]

68. Blanc FX, Sok T, Laureillard D, et al. Earlier versus later start of antiretroviral therapy in HIVinfected adults with tuberculosis. N Engl J Med. 2011; 365(16):1471-81. [PubMed: 22010913] 
69. Havlir DV, Kendall MA, Ive P, et al. Timing of antiretroviral therapy for HIV-1 infection and tuberculosis. N Engl J Med. 2011; 365(16):1482-91. [PubMed: 22010914]

70. Heath L, Fox A, McClure J, et al. Evidence for limited genetic compartmentalization of HIV-1 between lung and blood. PLoS One. 2009; 4(9):e6949. [PubMed: 19759830]

71. Iriart X, Witkowski B, Cassaing S, et al. Alveolar and blood T lymphocyte profiles in Pneumocystis jirovecii-positive patients: effects of HIV status. J Infect Dis. 2011; 204(4):544-53. [PubMed: 21791656]

72. Jambo KC, Sepako E, Fullerton DG, et al. Bronchoalveolar CD4+ T cell responses to respiratory antigens are impaired in HIV-infected adults. Thorax. 2011; 66(5):375-82. [PubMed: 21357587]

73. Rubbo PA, Tuaillon E, Bollore K, et al. The potential impact of CD4+ T cell activation and enhanced Th1/Th2 cytokine ratio on HIV-1 secretion in the lungs of individuals with advanced AIDS and active pulmonary infection. Clin Immunol. 2011; 139(2):142-54. [PubMed: 21345739]

74. Tachado SD, Li X, Bole M, et al. MyD88-dependent TLR4 signaling is selectively impaired in alveolar macrophages from asymptomatic HIV+ persons. Blood. 2010; 115(17):3606-15.

[PubMed: 20197549] 


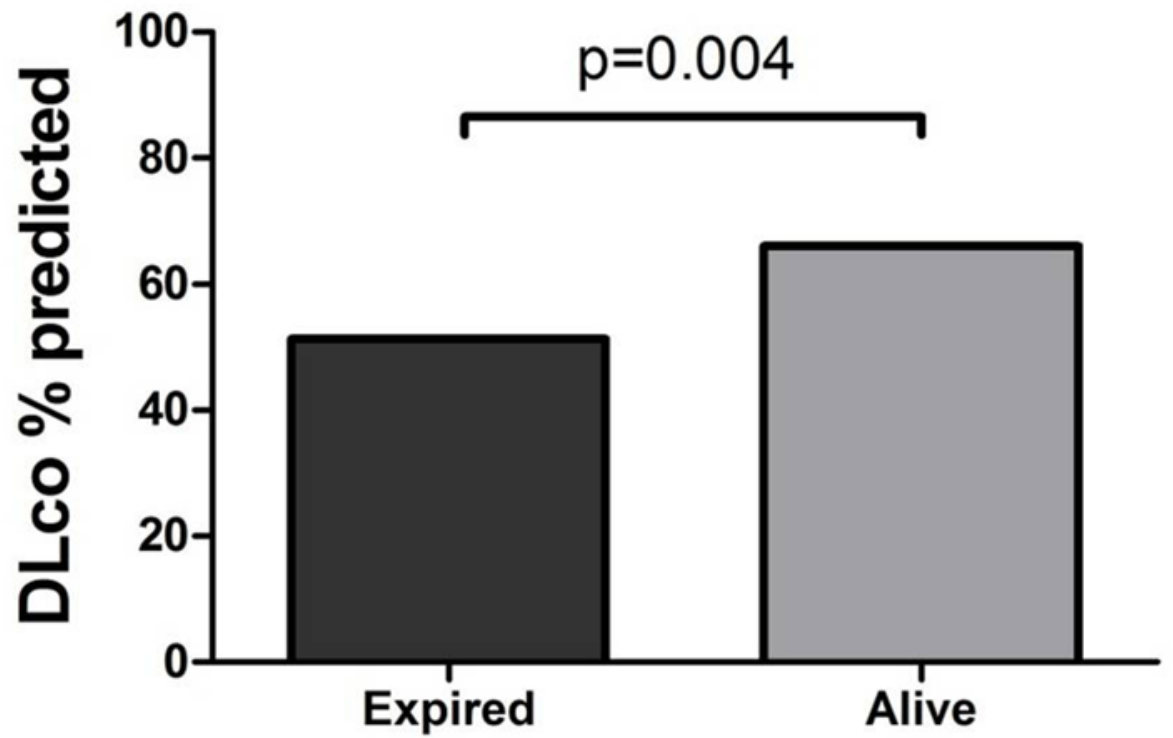

Figure 1.

Mean diffusing capacity for carbon monoxide $\left(\mathrm{DL}_{\mathrm{CO}}\right) \%$ predicted in $\mathrm{HIV}$-infected participants by vitality status after 3 years follow-up from the time of $\mathrm{DL}_{\mathrm{CO}}$ measurement. 


\begin{tabular}{|c|c|c|c|c|c|c|}
\hline 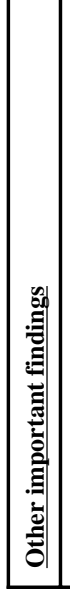 & 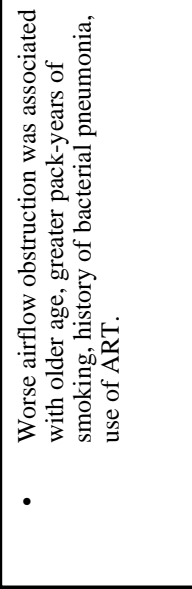 & 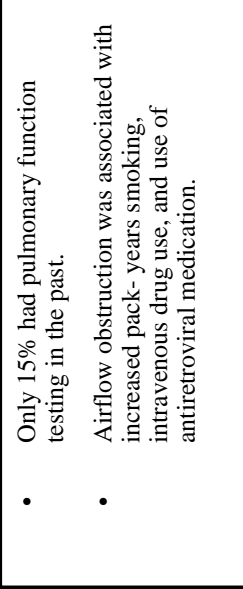 & 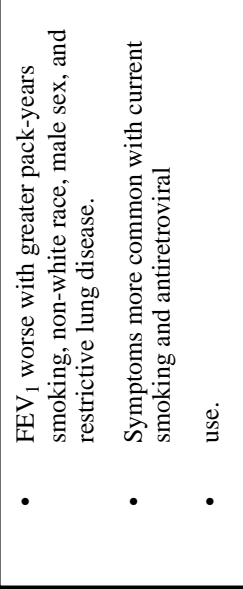 & 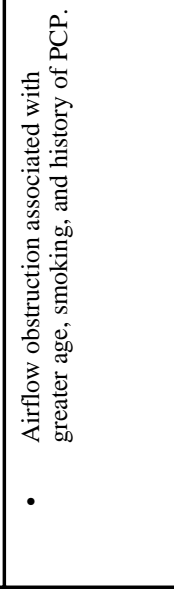 & 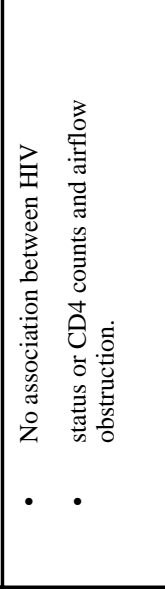 & 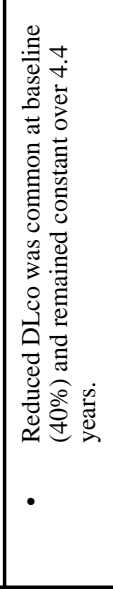 \\
\hline 量 & 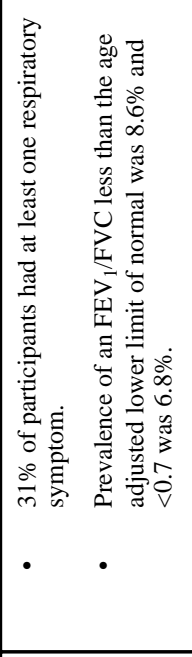 & 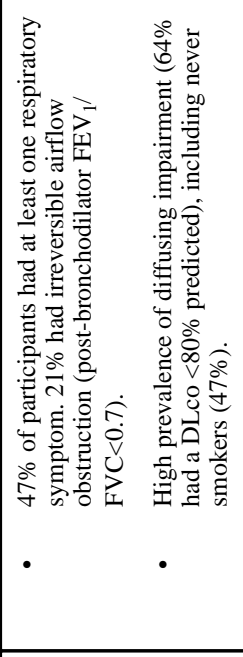 & 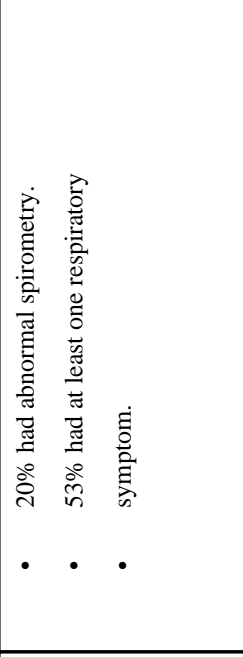 & 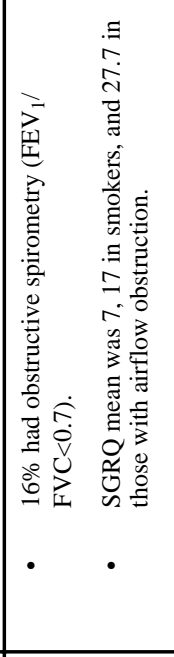 & 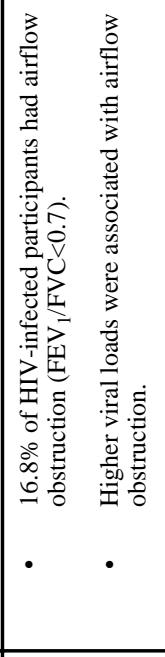 & 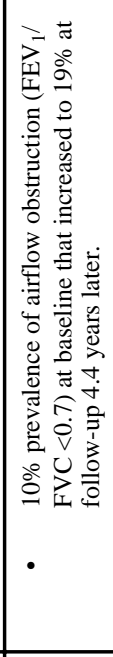 \\
\hline 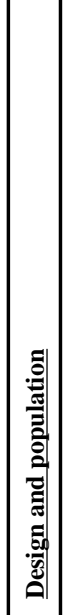 & 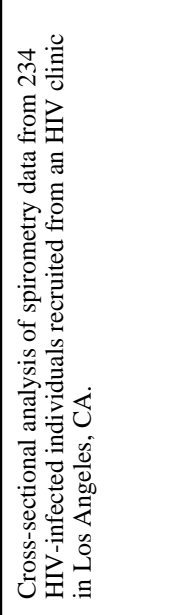 & 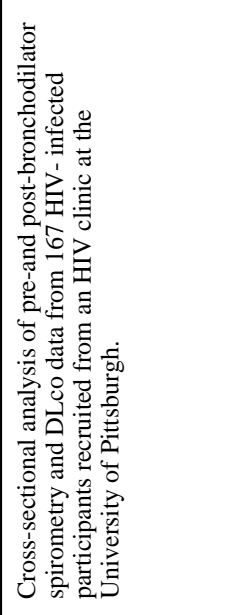 & 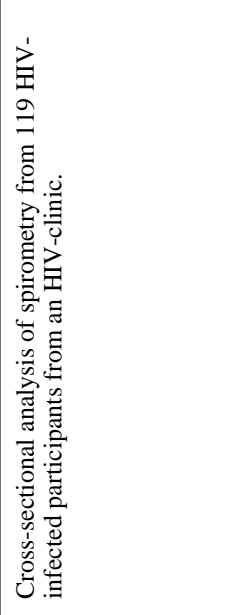 & 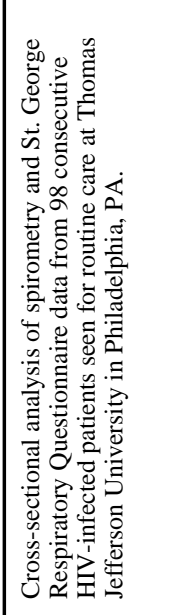 & 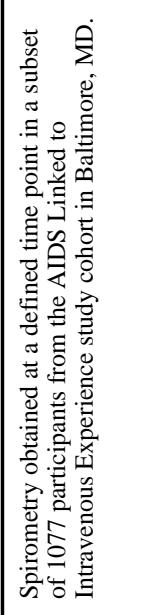 & 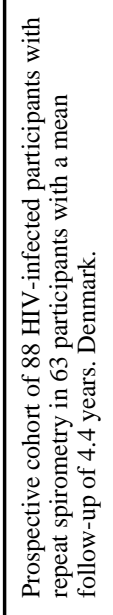 \\
\hline | & 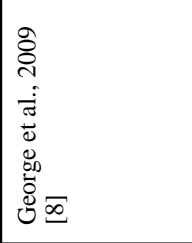 & 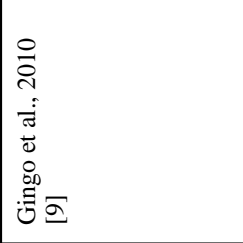 & 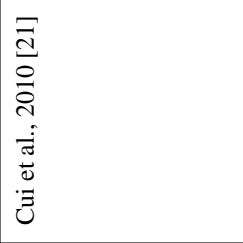 & 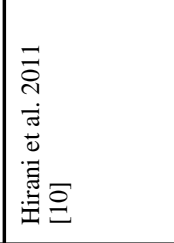 & 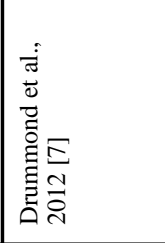 & 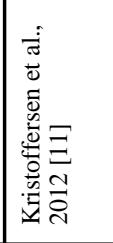 \\
\hline
\end{tabular}

